This is the peer reviewed version of the following article: [Qi, C., Chen, H., Sun, Y., Shen, L., Li, X., Fu, Q., and Liu, Y. (2020). Facile preparation of robust superhydrophobic surface based on multi-scales nanoparticle. Polymer Engineering \& Science 60 which has been published in final form at https://doi.org/10.1002/pen.25416. This article may be used for non-commercial purposes in accordance with Wiley Terms and Conditions for Self-Archiving." 


\section{Facile preparation of robust superhydrophobic surface based on multi-scales nanoparticle}

Chunhong $\mathrm{Qi}^{1}$, He Chen ${ }^{1}$, Youyi Sun ${ }^{1 *}$, Luyan Shen ${ }^{1}$, Xiaolin $\mathrm{Li}^{1}$, Qiang $\mathrm{Fu}^{2}$, Yaqing $\mathrm{Liu}^{1 *}$ 1.Shanxi Province Key Laboratory of Functional Nanocomposites, North University of China, Taiyuan 030051, P.R.China.

2. School of Civil and Environmental Engineering, University of Technology Sydney, Ultimo NSW 2007, Australia.

Abstract: A new superhydrophobic surface based on multi-scales nanoparticle was developed to improve the robustness and reproducibility. The influence of multi-scale nanoparticles on the wettability and durability of superhydrophobic surface was investigated in detail. The superhydrophobic surface with optimized composition did not only show high contact angle of $160 \sim 166.3^{\circ}$, but also exhibited good durability to mechanical, chemical and thermal environment. Furthermore, the superhydrophobic surface was evaluated for application in anticorrosion, anti-icing and self-cleaning. This study thus opens up an avenue for the development of robust superhydrophobic surface based on polymer nanocomposite coating for various potential applications.

Keywords: superhydrophobic coating, FEVE, micro-nanostructure, mechanical, chemical, thermal stability.

corresponding author: Fax: 86-351-3559669

E-mail address: syyi@pku.edu.cn(YY Sun); lyqzgz2010@163.com(YQ Liu) 


\section{Introduction}

During the past decades, superhydrophobic surface based on polymer nanocomposite has received extensive attention due to their low-cost and facile preparation for application in corrosion protection, drag reduction, self-cleaning, oil-water separation, anti-icing, etc[1-5]. Generally, to achieve superhydrophobicity, large surface roughness of polymer nanocomposite was needed and prepared by enhancing concentration of inorganic particles[3-4]. However, these surfaces displayed low mechanical durability, such as poor wear resistance, impact resistance, or adhesion strength. The hydrophobicity of these surfaces was easily reduced under external forces. At the same time, these surfaces were also easily damaged, forming cracks, spalling and so on. Therefore, there was a great deal of efforts to enhance the mechanical durability of superhydrophobic surface via fabricating different types of particles such as various particles, doping content, multi-scales[6-9]. Among these methods, introduction of multi-scales particle was the effective method to improve the mechanical durability of superhydrophobic coatings[9]. For example, an ethanolic suspension of perfluorosilane modified multi-scale titanium dioxide $\left(\mathrm{TiO}_{2}\right)$ nanoparticles were coated on both hard and soft substrates under the assistant of adhesion agents. The coating displayed a large water contact angle (WCA) of $157.0^{\circ}$ after finger-wipe, knife-scratch and even 40 abrasion cycles with sandpaper[10]. The 3-aminopropyltrimethoxysilane (APTES)-functionalized multi-scale silica nanoparticles $(100 \mathrm{~nm}$ and $20 \mathrm{~nm})$ were coated onto different substrates, forming superhydrophobic surface with a WCA of greater than $160^{\circ}[11]$. The composite coating composed of polydimethylsiloxane (PDMS) and multi-scale silicon dioxide $\left(\mathrm{SiO}_{2}\right)$ nanoparticles were painted on the surface of magnesium alloys, affording a superhydrophobic and mechanically robust coating, which could maintain its origin WCA $\left(133 \sim 153^{\circ}\right)$ under 50 abrasion cycles with sandpaper[12]. However, it still presents a contradiction between superhydrophobicity and mechanical durability, in which the surface with excellent superhydrophobicity still shows poor mechanical stability. As well-known, fluoroethylene vinyl ether (FEVE) has good heat-durability, wear-resistance, outstanding water-repellency, strong adherence and anti-ultraviolet[13-15]. From above respects, the coating based on multi-scale nanoparticles and FEVE maybe simultaneously exhibit excellent superhydrophobicity and mechanical durability. However, the preparation of superhydrophobic surface based on FEVE nanocomposite has been rarely studied. 
Herein, we employed two different types and sized nanoparticles, 30.0nm $\mathrm{SiO}_{2}$ and $300.0 \mathrm{~nm} \mathrm{TiO}_{2}$ nanoparticles, and FEVE to construct composite coatings with a novel micro-nano rough surfaces. Of particular note, the $\mathrm{SiO}_{2}$ nanoparticles were firstly modified with $N$-octyltriethoxysilane (OTS) to further enhance their compatibility to FEVE and reduce the surface energy of coating. The resultant $\mathrm{TiO}_{2} / \mathrm{SiO}_{2} / \mathrm{FEVE}$ nanocomposite coatings do not only show good superhydrophobicity, but also possess good thermal and mechanical stability. This study is expected to introduce an effective approach for preparing durable superhydrophobic coatings for various practical applications.

\section{Experimental}

\subsection{Materials}

Silica $(\mathrm{D}=30 \mathrm{~nm})$ and $\mathrm{TiO}_{2}(\mathrm{D}=300 \mathrm{~nm})$ were purchased from Beijing deke daojin technology co. Ltd. Fluoroethylene vinyl ether (FEVE) and curing agent were purchased from Shanxi Dongfanghong Paint Co., Ltd. Xylene was purchased from Tianjin guangfu technology development Co., Ltd. Q235 and transparent glass slides were purchased from the local chemical market. All reagents were used without further purification.

\subsection{Chemical modification of $\mathrm{SiO}_{2}$ nanoparticles}

The $\mathrm{SiO}_{2}$ nanoparticles were modified with $\mathrm{N}$-octyltriethoxysilane (OTS) as shown in Scheme 1. Firstly, $10 \mathrm{~g} \mathrm{SiO}_{2}$ nanoparticle was dispersed in $100 \mathrm{~mL}$ toluene to form a homogeneous dispersion. Then, $10 \mathrm{~mL}$ OTS was added into the mixture and stirred continuously at $120^{\circ} \mathrm{C}$ for $12 \mathrm{~h}$. After then, the reaction mixture was cooled to room temperature and washed with toluene and ethanol for several times. The hydrophobic $\mathrm{SiO}_{2}$ nanoparticles were dryed at $65^{\circ} \mathrm{C}$.

\section{Scheme 1.}

\subsection{Preparation of $\mathrm{TiO}_{2} / \mathrm{SiO}_{2} / \mathrm{FEVE}$ nanocomposite coating}

The $\mathrm{TiO}_{2} / \mathrm{SiO}_{2} / \mathrm{FEVE}$ nanocomposite coating was prepared via a simple spraying method. Firstly, a certain amount of modified $\mathrm{SiO}_{2}$ and $\mathrm{TiO}_{2}$ was dispersed in xylene at room temperature and sonicated for $10.0 \mathrm{~min}$ to form a uniform dispersion. Typically, FEVE and curing agent were dispersed in xylene under ultrasonication for $10.0 \mathrm{~min}$ and the mass ratio of FEVE to the curing agent was 10:1. Then, the modified dispersion was added into the mixture of FEVE and curing agent to form the paint. Finally, this paint based on nanoparticles and FEVE was spray-coated on the substrates and then cured at room temperature for $24 \mathrm{~h}$. A series of coatings were 
fabricated by varying the proportions of $\mathrm{SiO}_{2}$ and $\mathrm{TiO}_{2}$ (i.e. 1.5:3 and 2:3).

\subsection{Instruments and characterization}

The morphology of the obtained samples was observed by Field emission scanning electron microscopy (SEM, Su-8010) and metallographic microscope (IM300).

Static WCA and sliding angles (CA) were measured at ambient temperature using an optical contact angle meter (DSA100, Germany) and the volume of droplets was 5 and $10.0 \mu \mathrm{L}$, respectively.

The tape and peel tests were conducted by ASTM D 3359-09 and GB/T 5210-2006, respectively to measure adhesion strength of coating with the substrates.

The impact resistance was performed according to GB/T1732-1993 by falling weight test. The impact energy $(E, \mathrm{~J})$ was further calculated to evaluate the impact resistance as shown in following.

$E=\mathrm{m} \cdot \mathrm{g} \cdot \mathrm{H}$

Where, $\mathrm{m}, \mathrm{g}$ and $\mathrm{H}$ are the mass of the impinging ball $(1.0 \mathrm{Kg})$, the gravity $(9.81$ $\mathrm{m} / \mathrm{s}^{2}$ ) and the height of the weight fall, respectively. The impact height was successively increased in 5-cm-steps and 1-cm-step. All impact sites were visually evaluated by means of an optical stereo microscope at 10.0 magnification. The failure criterion was the impact energy value (in J) that caused radial cracking in the coating system.

\section{Results and Discussion}

The micro-structure and WCA of FEVE coating, $\mathrm{TiO}_{2} / \mathrm{FEVE}$ composite coating and $\mathrm{TiO}_{2} / \mathrm{SiO}_{2} / \mathrm{FEVE}$ composite coating were characterized and compared as shown in Fig.1. As shown in Fig.1A, the pristine FEVE coating showed a relatively smooth surface and lots of cracks. As expected, the pristine FEVE coating displayed a small WCA of $88.3^{\circ}$, indicating a hydrophilicity as shown in inset of Fig.1A. After doping $30 \mathrm{wt} \% \mathrm{TiO}_{2}$ particles (D 300nm) into FEVE matrix, the composite coating still showed a relatively smooth surface, yet it showed few cracks. These results indicated that the $\mathrm{TiO}_{2}$ particles could improve the film formation of FEVE resin, meanwhile suppress the formation the cracks. As shown in Fig.1C, the surface roughness of composite coating obviously increased, which was attributed to the synergistic effect of $15 \mathrm{wt} \% \mathrm{SiO}_{2}$ (30nm in diameter) and $30 \mathrm{wt} \% \quad \mathrm{TiO}_{2}$ nanoparticles $(300 \mathrm{~nm}$ in diameter). After introduction of $\mathrm{TiO}_{2}$ and modified $\mathrm{SiO}_{2}$ nanoparticles, the composite coatings exhibited an larger WCA than $90.0^{\circ}$, suggesting a hydrophobic nature as 
shown in inset of Fig.1B and $1 \mathrm{C}$. When the content of $\mathrm{SiO}_{2}$ nanoparticles was further improved to $20 \mathrm{wt} \%$, the surface of composite coating clearly showed porous structure, leading to a greater surface roughness. The composite coating with $30 \mathrm{wt} \% \mathrm{TiO}_{2}$ and $20 \mathrm{wt} \% \mathrm{SiO}_{2}$ showed the biggest WCA of $166.3^{\circ}$ as shown in inset of Fig.1D, indicating a surperhydrophobicity. On a rough hydrophobic surface, the WCA follows the Cassie-Baxter equation (1), which is theoretically positively related to the air fraction $(f)$ in the composite surface.

$$
\cos \theta_{c}=f\left(\cos \theta_{0}+1\right)-1
$$

Where $\theta_{c}$ and $\theta_{0}$ are the WCA of water droplets on the rough and smooth surfaces with the same chemical composition, respectively. $f$ is the fraction of solid-liquid contact area. The micro-nano surface structure is conducive to produce a higher surface roughness, so that more air can be captured as shown in Fig.2F. The air layer can serve as a physical barrier to reduce the contact area of water droplets and the surface. Together with the low surface energy derived from OTS, the surface can achieve excellent superhydrophobicity $\left(166.3^{\circ}\right)$.

\section{Fig.1.}

At present, the superhydrophobic surface with micro and/or nano coarse structures are usually easy to be destroyed by mechanical forces, thus losing their superhydrophobicity. In order to solve this tough problem, we chose FEVE resin with good film-forming and bonding properties as a binder, which greatly improved the bonding strength between the coating and substrate. Here, the tape method was firstly performed to evaluate adhesion of composite coating with metal substrate as shown in Fig.2A-D. According to ASTM D3359, it ranged from 0B (complete removal of coating film lattices) to 5B (intact lattices with completely smooth edges)[17]. Visible detachment of pristine FEVE coating after the tape test was clearly observed as shown in Fig.2A, indicating a adhesion level of 3B between FEVE coating and metal substrate based on the descriptive scale. As shown in Fig.2B-D, the intact lattices with completely smooth edges was observed for the composite coatings, indicating the highest adhesion level of 5B. The adhesion level of composite coating was obviously improved from $3 \mathrm{~B}$ to $5 \mathrm{~B}$, indicating a stronger adhesion of composite coating with substrate comparing to pure FEVE coating. The result was attributed to that the inorganic particles could improve mechanical strength of FEVE segments. Of particular, the composite coatings still maintained their superhydrophobicity after tape 
test as shown in inset of Fig.2D. The adhesion between coating and substrate was further detected by peel tests as shown in Fig.2E-H. The adhesion strength between pristine FEVE and substrate was only about 3.2MPa. After the introduction of $\mathrm{TiO}_{2}$ particles, the adhesion strength was greatly improved to $14.0 \mathrm{MPa}$. Although this value slightly decreased from $14.0 \mathrm{MPa}$ to $8.9 \mathrm{MPa}$ when introducing $20 \mathrm{wt} \% \quad \mathrm{SiO}_{2}$ nanoparticles, the composite coating still possessed large adhesion strength with metal substrates. As well-known, the adhesion strength between coating and substrate was mainly attributed to polymer matrix. Generally, the polymer coating with larger mechanical strength showed adhesion strength. So, the $\mathrm{TiO}_{2} / \mathrm{FEVE}$ coating showed larger adhesion strength comparing to pure FEVE coating. However, when the content of inorganic particles was further increased, these inorganic particles replaced the FEVE to contact with substrate. At the same time, the mechanical strength was decreased due to aggregate of inorganic particles. So, it showed a decrease of adhesion strength after introduction of more $\mathrm{SiO}_{2}$ nanoparticles.

\section{Fig.2.}

The impact resistance of various coatings was characterized and compared by falling weight test as shown in Fig.3. After the falling weight test, the damage morphology of pristine FEVE coating were displayed in Fig.3B(a). It clearly showed lateral cracking and severe coating detachment at the impact edge, indicating a poor impact resistance of $\sim 0.98 \mathrm{~J}$ (corresponding to $10.0 \mathrm{~cm}$ height). In contrast, these composite coatings showed plastic deformation and few visible cracks as shown in Fig.3B-D. In addition, the impact energy of composite coating based on $\mathrm{TiO}_{2}$ was dramatically improved from $0.98 \mathrm{~J}$ to $8.72 \mathrm{~J}$ (corresponding to $89 \mathrm{~cm}$ height) as shown in Fig.3A. At the same time, it was found that the impact energy of the composite coating slight decreased to $6.96 \mathrm{~J}$ (corresponding to $71.0 \mathrm{~cm}$ height) after the incorporation of $\mathrm{SiO}_{2}$ nanoparticles. These results were attributed to the reinforcing effect of $\mathrm{TiO}_{2}$ and $\mathrm{SiO}_{2}$, agreeing well with the results obtained from adhesion tests. A proper amount of $\mathrm{SiO}_{2}$ could work synergistically with $\mathrm{TiO}_{2}$ to form a uniform and effective network structure in the matrix, thus maintaining excellent impact resistance.

Fig.3.

Importantly, the bending experiments were also tested to further verify aforementioned mechanical stability of the composite coating with $30 \mathrm{wt} \% \mathrm{TiO}_{2}$ and $20 \mathrm{wt} \% \mathrm{SiO}_{2}$ as shown in Fig.4. The glass rod with a radius (R) of $7.0 \mathrm{~mm}$ was used as the bending center and the angle between the bent coating and the horizontal plane 
was defined as the bending angles $\theta$ and $-\theta$ as shown in Fig.4A. The corresponding WCA was recorded after bending tests at different angles as shown in Fig.4B-C. The WCA of composite coating was larger than $160^{\circ}$ after bending at different angles. This result indicated that the composite coating could maintain excellent superhydrophobicity at different bending increments. In addition, the bending angle from $-90^{\circ}$ (maximum downward bending) to $90^{\circ}$ (maximum upward bending) was defined as a bending cycle, and the WCA of composite coating was measured as a function of the bending cycles. It was found that the composite coating still showed a large WCA of $156.0^{\circ}$ after 30 bending cycles as shown in Fig.4D. As shown in Fig.4E, no cracks were observed on the surface of composite coating after 30 bending cycles. These results further demonstrated the presented composite coatings with excellent bending resistance, flexibility, adhesion ability and mechanical durability.

\section{Fig.4.}

The sandpaper abrasion test was carried out to examine the wear resistance of composite coating with $30 \mathrm{wt} \% \mathrm{TiO}_{2}$ and $20 \mathrm{wt} \% \mathrm{SiO}_{2}$ as shown in Fig.5. Fig.5A showed the schematic illustration of the sandpaper abrasion test. The coating was placed face-down to sandpaper (standard glasspaper, grit no. 240) under a load of $100 \mathrm{~g}$ and moved for $10 \mathrm{~cm}$, followed by rotated by $90^{\circ}$ and moved for another $10 \mathrm{~cm}$. We defined this process as one abrasion cycle, ensuring both longitudinal and transverse friction could be carried out simultaneously during the friction process of each cycle. As shown in Fig.5B, the WCA and the sliding angle of composite coating slightly decreased from $166.3^{\circ}$ to $158.6^{\circ}$ and increased from $1.0^{\circ}$ to $14.0^{\circ}$ after 50 abrasion cycles, respectively. The result indicated that the superhydrophobicity of composite coating was reserved under mechanical wear. The water drop on composite coating before and after 50 abrasion cycles was slight change as shown in inset of Fig.5B. The surface structure of composite coating before and after friction was also characterized and compared by the SEM images as shown in Fig.5C and 5D, respectively. The composite coating before and after friction obviously displayed similar surface morphology. These results demonstrated the presented composite coatings with excellent wear resistance. The good wear resistance was attributed to relatively small surface roughness and the incorporation of micro size particles with excellent wear resistance.

\section{Fig.5.}


The thermal stability of the presented composite coating was investigated by thermogravimetry instrument at a heating rate of $10^{\circ} \mathrm{C} / \mathrm{min}$ in air. As shown in Fig.6A, a bit weight loss of composite coating was observed below $300^{\circ} \mathrm{C}$, suggesting excellent thermal stability below $300^{\circ} \mathrm{C}$. When the temperature increased over $300^{\circ} \mathrm{C}$, the weight loss of composite coating increased to ca. $40 \mathrm{wt} \%$, resulting from the thermal degradation of FEVE resin. In addition, this result agreed well with the doping content of $\mathrm{SiO}_{2}$ and $\mathrm{TiO}_{2}$ particles (totally ca. 50wt\%) in FEVE matrix. The WCA of composite coating as a function of treatment temperature was also characterized as shown in Fig.6B. The composite coating was heated in a muffle furnace at $50^{\circ} \mathrm{C} \sim 400^{\circ} \mathrm{C}$ for 3 hours. It was found that the WCA of composite coating maintained around $155.0^{\circ}$ below $300^{\circ} \mathrm{C}$. When the treatment temperature increased over $350^{\circ} \mathrm{C}$, the WCA dramatically decreased to close $0^{\circ}$. This result was attributed to the decomposition of FEVE. These results demonstrated that the composite coating had excellent thermal stability from $25^{\circ} \mathrm{C}$ to $300^{\circ} \mathrm{C}$.

\section{Fig.6.}

The self-cleaning property of various coatings was characterized and compared as shown in Fig.7. It was clearly observed that the contaminant particles could be easily removed from the composite coating with $30 \mathrm{wt} \% \quad \mathrm{TiO}_{2}$ and $20 \mathrm{wt} \% \quad \mathrm{SiO}_{2}$ nanoparticles by the rolled water droplets. In this process, the surface of the inclined coating was completely cleaned as shown in Fig.7A. The good self-cleaning property of the composite coating was mainly attributed to the superhydrophobic surface, forming air film. Such air film could effectively reduce the direct contact between the contaminant and the coating. Thus, when water droplets passed through the surface, the contaminants were carried away. Fig.7E showed the WCA of the composite coating as a function of self-cleaning cycles. In the experiment, methyl orange was used to simulate dust to help visualization. It was found that the dust on the coating could be completely removed after 50 cycles. In contrast, the contaminant particles were difficult to be removed from other coatings by the rolled water droplets (in Fig.7B-D). The result was attributed to the low hydrophobicity of other coatings. These results strongly indicated that the presented composite coatings with with $30 \mathrm{wt} \% \mathrm{TiO}_{2}$ and $20 \mathrm{wt} \% \mathrm{SiO}_{2}$ had excellent self-cleaning ability.

Fig.7.

The anti-icing ability of various coatings was also evaluated and compared by using high-speed camera as shown in Fig.8. It was found that the ice was grown from 
bottom to the top after a cooling period. When the water began to freeze, the transparent center of the condensed water vanished due to the difference in reflectivity between water and ice. It clearly showed that the froze time and and precooling time of water droplet on pristine FEVE coating was about $69 \mathrm{~s}$ and $30 \mathrm{~s}$ at $-25^{\circ} \mathrm{C}$, respectively as shown in Fig.8A. In contrast, the froze time and precooling time of water droplet on composite coating with $30 \mathrm{wt} \% \mathrm{TiO}_{2}$ and $20 \mathrm{wt} \% \mathrm{SiO}_{2}$ was prolonged to 389 s and 215 s, respectively as shown in Fig.8D. In general, these results were mainly caused by the following three reasons. Firstly, the composite coating with $30 \mathrm{wt} \% \quad \mathrm{TiO}_{2}$ and $20 \mathrm{wt} \% \quad \mathrm{SiO}_{2}$ could provide superhydrophobic surface,greatly reducing the contact area between droplets and the coating surface[18-19]. Secondly, the large amount of air layer trapped in the superhydrophobic surface acted as a good insulation layer to prevent the droplets from freezing, thus delaying the time when the droplets reached the nucleation temperature. Finally, the composite coating showed small surface roughness, providing good free-energy barrier and delaying the formation of ice nucleation. These results indicated that the present composite superhydrophobic coating with $30 \mathrm{wt} \% \mathrm{TiO}_{2}$ and $20 \mathrm{wt} \% \mathrm{SiO}_{2}$ had good anti-icing ability.

\section{Fig.8.}

Superhydrophobic coating was considered to be an effective metal anticorrosion method due to its excellent water repellency. Here, the anticorrosion of various coatings were characterized and compared by Tafel polarization curves in the $3.5 \mathrm{wt} \%$ $\mathrm{NaCl}$ solutiou as shown in Fig.9A. The values of corrosion current densities ( $\left.I_{\text {corr }}\right)$, corrosion potentials $\left(E_{\text {corr }}\right)$, polarization resistance $\left(R_{\mathrm{p}}\right)$ and corrosion rate $\left(V_{\text {corr }}\right)$ were calculated according the Tafel polarization curves as shown in Table 1. It clearly showed that the $E_{\text {corr }}$ was shifted towards positive direction with increasing in hydrophobic performance as shown in Fig.9A. Specifically, the $E_{\text {corr }}$ of composite coating with $30 \mathrm{wt} \% \mathrm{TiO}_{2}$ and $20 \mathrm{wt} \% \mathrm{SiO}_{2}$ covered $\mathrm{Fe}$ was shifted positively for about $0.67 \mathrm{~V}$ comparing with the pristine FEVE coated Fe. This suggested that the composite coating with $30 \mathrm{wt} \% \mathrm{TiO}_{2}$ and $20 \mathrm{wt} \% \mathrm{SiO}_{2}$ could retard the dissolution of Fe from seawater due to superhydrophobicity [20]. In addition, the $I_{\text {corr }}$, and $V_{\text {corr }}$ values of coatings covered metal decreased with increasing their hydrophobicity as shown in Table 1 . The $I_{\text {corr }}$, and $V_{\text {corr }}$ values of composite coating with $30 \mathrm{wt} \% \mathrm{TiO}_{2}$ and $20 \mathrm{wt} \% \mathrm{SiO}_{2}$ covered $\mathrm{Fe}$ both decreased by about two orders of magnitude comparing with that of pristine FEVE coated Fe. It was well-known that the lower $I_{\text {corr }}$ 
or $V_{\text {corr }}$ showed better anticorrosive performance[21-22]. In other words, the composite coating with $30 \mathrm{wt} \% \quad \mathrm{TiO}_{2}$ and $20 \mathrm{wt} \% \quad \mathrm{SiO}_{2}$ showed best anticorrosion comparing to other coatings. Above result was further confirmed by the Nyquist plots as shown in Fig.9B. All samples displayed a semicircle at high frequency, which represented the charge transfer resistance $\left(R_{\mathrm{ct}}\right)$ at the metal/solution interface. A larger semicircle suggested a higher $R_{\mathrm{ct}}$ value, meaning a longer path of the ion diffusion from aqueous solution to metal substrate. The $R_{\mathrm{ct}}$ values obviously increased with increasing in hydrophobicity of coating. Specifically, the $R_{c t}$ of composite coating with $30 \mathrm{wt} \% \mathrm{TiO}_{2}$ and $20 \mathrm{wt} \% \mathrm{SiO}_{2}$ covered $\mathrm{Fe}$ was about $410 \mathrm{~K} \Omega \cdot \mathrm{cm}^{2}$, which was 10 times higher than that of the pristine FEVE coating covered Fe. Generally, a larger $R_{\mathrm{ct}}$ value indicated a lower corrosion rate [23]. The result further indicated the good anticorrosion performance of composite coating with $30 \mathrm{wt} \% \mathrm{TiO}_{2}$ and $20 \mathrm{wt} \% \mathrm{SiO}_{2}$. The result was attributed to superhydrophobicity, capturing a lot of air and forming a stable air film on composite coating. The air layer could effectively prevent the diffusion of corrosive $\mathrm{Cl}^{-}$ions from water to substrate. In addition, the FEVE resin with good barrier to corrosive $\mathrm{Cl}^{-}$ions was also key role for the excellent anticorrosion.

Fig.9.

Table 1.

\section{Conclusions}

In summary, a novel superhydrophobic coating based on multi-scale nanoparticles was developed and prepared by one-step spray-coating. The superhydrophobic coating with multi-scale structure did not only exhibit good superhydrophobicity, but also possessed excellent mechanical and thermal stability. Furthermore, the presented coatings showed good self-cleaning, anti-icing and anticorrosion performance. This work provides a new approach to improve durability of superhydrophobic surface, which has great potential in various practical applications.

\section{Acknowledgments}

The authors are grateful for the support of the National Natural Science Foundation of China under grants (51773184 and U1810114), and Shanxi Provincial Natural Science Foundation of China (201701D121046 and 201803D421081).

Reference

[1]Y.Ye, D.Zhang, J.Li, T.Liu, J.Pu, H.Zhao, L.Wang, One-step synthesis of 
superhydrophobic polyhedral oligomeric silsesquioxane-graphene oxide and its application in anti-corrosion and anti-wear fields, Corrosion Science, 147 (2019) 9-21.

[2]G.B. Hwang, A. Patir, K. Page, Y. Lu, E. Allan, I.P. Parkin, Buoyancy increase and drag-reduction through a simple superhydrophobic coating, Nanoscale, 9 (2017) 7588-7594.

[3]W.S.Wong, Z.H.Stachurski, D.R.Nisbet, A.Tricoli, Ultra-Durable and Transparent Self-Cleaning Surfaces by Large-Scale Self-Assembly of Hierarchical Interpenetrated Polymer Networks, ACS applied materials \& interfaces, 8 (2016) 13615-13623.

[4]J.Lv, XQ.Yin, R.G.Li, J.H. Chen, Q.Lin, L. Zhu, Superhydrophobic PCL/PS composite nanofibrous membranes prepared through solution blow spinning with an airbrush for oil adsorption, Polymer Engineering \& Science, 59(2018)E171-E181.

[5]Z.Q.Yuan, J.P. Bin, X.Wang, Q.L.Liu, D.J. Zhao, H. Chen, H.Y. Jiang, Preparation and anti-icing property of a lotus-leaf-like superhydrophobic low-density polyethylene coating with low sliding angle, Polymer Engineering \& Science, 52(2012)2310-2315.

[6]Y.Zhang, L.Zhang, Z.Xiao, S.Wang, X.Yu, Fabrication of robust and repairable superhydrophobic coatings by an immersion method, Chemical Engineering Journal, 369 (2019) 1-7.

[7]D.Zhi, Y.Lu, S.Sathasivam, I.P.Parkin, X.Zhang, Large-scale fabrication of translucent and repairable superhydrophobic spray coatings with remarkable mechanical, chemical durability and UV resistance, Journal of Materials Chemistry A, 5 (2017) 10622-10631.

[8]W.Peng, X.Gou, H.Qin, M.Zhao, X.Zhao, Z.Guo, Robust $\mathrm{Mg}(\mathrm{OH})_{2}$ /epoxy resin superhydrophobic coating applied to composite insulators, Applied Surface Science, 466 (2019) 126-132.

[9]Z.Cui, L.Yin, Q.Wang, J. Ding, Q.Chen, A facile dip-coating process for preparing highly durable superhydrophobic surface with multi-scale structures on paint films, $\mathrm{J}$ Colloid Interface Sci, 337 (2009) 531-537.

[10] H.Wang, F.Sun, C.Wang, Y.Zhu, H.Wang, A simple drop-casting approach to fabricate the super-hydrophobic PMMA-PSF-CNFs composite coating with heat-, wear- and corrosion-resistant properties, Colloid and Polymer Science, 294 (2015) 303-309. 
[11]R.G.Karunakaran, C.H.Lu, Z.Zhang, S.Yang, Highly transparent superhydrophobic surfaces from the co-assembly of nanoparticles $(\leq 100 \mathrm{~nm})$, Langmuir : the ACS journal of surfaces and colloids, 27 (2011) 4594-4602.

[12]J.Xie, J.Hu, X.Lin, L.Fang, F.Wu, X.Liao, H.Luo, L.Shi, Robust and anti-corrosive $\mathrm{PDMS} / \mathrm{SiO}_{2}$ superhydrophobic coatings fabricated on magnesium alloys with different-sized $\mathrm{SiO}_{2}$ nanoparticles, Applied Surface Science, 457 (2018) 870-880.

[13]Y.Wu, X.Li, C.Mi, L.Zong, X.Wang, Preparation and characterization of perfluorine- $\mathrm{SiO}_{2}$ nanoparticles and superhydrophobic fluorosilicone/silica hybrid composite coating, Applied Physics A, 125 (2019).

[14]J.Zhang, C.Li, K.Yan, L.Shen, N.Bao, Influence of the Aspect Ratio of Sodium Iron Titanate Whiskers on the Mechanical and Tribological Performances of Fluorocarbon Composite Coatings, Coatings, 9 (2019) 683.

[15]Y.Zhou, MLi, X.Zhong, Z.Zhu, P.Deng, H.Liu, Hydrophobic composite coatings with photocatalytic self-cleaning properties by micro/nanoparticles mixed with fluorocarbon resin, Ceramics International, 41 (2015) 5341-5347.

[16]Y.Shen, H.Tao, S.Chen, Y.Xie, T.Zhou, T.Wang, J.Tao, Water repellency of hierarchical superhydrophobic Ti6Al4V surfaces improved by secondary nanostructures, Applied Surface Science, 321 (2014) 469-474.

[17]D.Kumar, L.Li, Z.Chen, Mechanically robust polyvinylidene fluoride (PVDF) based superhydrophobic coatings for self-cleaning applications, Progress in Organic Coatings, 101 (2016) 385-390.

[18]Y.Li, B.Li, X.Zhao, N.Tian, J.Zhang, Totally Waterborne, Nonfluorinated, Mechanically Robust, and Self-Healing Superhydrophobic Coatings for Actual Anti-Icing, ACS applied materials \& interfaces, 10 (2018) 39391-39399.

[19]X.Zhan, Y.Yan, Q.Zhang, F.Chen, A novel superhydrophobic hybrid nanocomposite material prepared by surface-initiated AGET ATRP and its anti-icing properties, J. Mater. Chem. A, 2 (2014) 9390-9399.

[20]A.C.de Leon, R.B.Pernites, R.C.Advincula, Superhydrophobic colloidally textured polythiophene film as superior anticorrosion coating, ACS applied materials \& interfaces, 4 (2012) 3169-3176.

[21]K.Cai, S.Zuo, S.Luo, C.Yao, W.Liu, J.Ma, H.Mao, Z.Li, Preparation of polyaniline/graphene composites with excellent anti-corrosion properties and their application in waterborne polyurethane anticorrosive coatings, RSC Adv., 6 (2016) 
95965-95972.

[22]M.Cui, Y.Shen, H.Tian, Y.Yang, H.Feng, J.Li, Influence of water adhesion of superhydrophobic surfaces on their anti-corrosive behavior, Surface and Coatings Technology, 347 (2018) 38-45.

[23]H.Hu, Y.He, Z.Long, Y.Zhan, Synergistic effect of functional carbon nanotubes and graphene oxide on the anti-corrosion performance of epoxy coating, Polymers for Advanced Technologies, 28 (2017) 754-762. 
Table 1. Analysis results of Tafel polarisation curves and electrochemical impedance spectroscopy of various coatings covered metal after immersion in a $3.5 \mathrm{wt} \% \mathrm{NaCl}$ aqueous solution.

Scheme 1. Schematic illustration of the fabrication processes for modified $\mathrm{SiO}_{2}$ nanoparticles.

Fig.1 SEM images of the various coatings, (A) pure FEVE, (B) FEVE with 30wt $\%$ $\mathrm{TiO}_{2}(300.0 \mathrm{~nm})$, (C) FEVE with $30 \mathrm{wt} \% \mathrm{TiO}_{2}(300.0 \mathrm{~nm})$ and $15 \mathrm{wt} \% \mathrm{SiO}_{2}(30.0 \mathrm{~nm})$, (D) FEVE with $30 \mathrm{wt} \% \mathrm{TiO}_{2}(300.0 \mathrm{~nm})$ and $20 \mathrm{wt} \% \mathrm{SiO}_{2}(30.0 \mathrm{~nm})$. (E) and (F) are the schematic diagram of composite coating with $\mathrm{TiO}_{2}$ and $\mathrm{TiO}_{2} / \mathrm{SiO}_{2}$, respectively.

Fig.2. Optical photographs of various coatings after (A-D) tape and (E-H) peel test. (A, E) pure FEVE, (B, F) FEVE with 30wt\% $\mathrm{TiO}_{2}(300.0 \mathrm{~nm}),(\mathrm{C}, \mathrm{G})$ FEVE with $30 \mathrm{wt} \% \mathrm{TiO}_{2}(300.0 \mathrm{~nm})$ and $15 \mathrm{wt} \% \mathrm{SiO}_{2}(30.0 \mathrm{~nm}), \quad(\mathrm{D}, \mathrm{H}) \mathrm{FEVE}$ with $30 \mathrm{wt} \% \mathrm{TiO}_{2}$ (300.0nm) and $20 \mathrm{wt} \% \mathrm{SiO}_{2}(30.0 \mathrm{~nm})$.

Fig.3. (A) The impact energy and (B) optical photographs of various coatings after impact resistance test, (a) pure FEVE, (b) FEVE with 30wt\% $\mathrm{TiO}_{2}(300.0 \mathrm{~nm})$, (c) FEVE with $30 \mathrm{wt} \% \mathrm{TiO}_{2}(300.0 \mathrm{~nm})$ and $15 \mathrm{wt} \% \mathrm{SiO}_{2}(30.0 \mathrm{~nm})$, (d) FEVE with $30 \mathrm{wt} \%$ $\mathrm{TiO}_{2}(300.0 \mathrm{~nm})$ and $20 \mathrm{wt} \% \mathrm{SiO}_{2}(30.0 \mathrm{~nm})$. Optical microscope of red part in composite coating with (C) $30 \mathrm{wt} \% \mathrm{TiO}_{2}\left(300.0 \mathrm{~nm}\right.$ ) and (D) $30 \mathrm{wt} \% \mathrm{TiO}_{2} / 20 \mathrm{wt} \% \mathrm{SiO}_{2}$. Fig.4. (A) Schematic illustration of bending test, (B) the WCA and (C) optical photographs of composite coating after bending at different angles, (D) the WCA of composite coatings as function of bending cycles, (E) SEM image of composite coatings after 30 bending cycles. The insets of (B) and (D) are the digital image of water droplet on coating.

Fig.5. (A) Schematic illustration of the sandpaper abrasion test, (B) WCA of composite coating as function of abrasion cycles, The SEM images of composite coating (C) before and (D) after friction, The insets of (B) are digital image of water droplets on the corresponding coating and profile images of the WCA of corresponding coating before and after 50 abrasion cycles.

Fig.6. (A) The TG curve of composite coating, (B) WCA of composite coating as function of treatment temperatures for $3 \mathrm{~h}$.

Fig.7. Optical photograph of the self-cleaning process on various coatings, (A) FEVE with $30.0 \mathrm{wt} \% \mathrm{TiO}_{2}(300.0 \mathrm{~nm})$ and $20.0 \mathrm{wt} \% \mathrm{SiO}_{2}(30.0 \mathrm{~nm})$, (B) FEVE with $30.0 \mathrm{wt} \%$

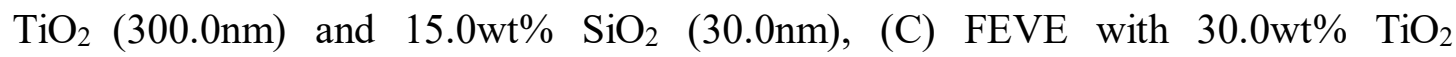


(300.0nm), (D) pure FEVE. (E) WCA of composite coating as function of self-cleaning cycles. The insets of $(\mathrm{E})$ are the optical photograph of the $50^{\text {th }}$ self-cleaning process on composite coatings.

Fig.8. Optical photograph of water droplet on various coatings at $-25.0^{\circ} \mathrm{C}$, (A) pure FEVE, (B) FEVE with 30.0wt\% $\mathrm{TiO}_{2}(300.0 \mathrm{~nm})$, (C) FEVE with $30.0 \mathrm{wt} \% \mathrm{TiO}_{2}$ (300.0nm) and $15.0 \mathrm{wt} \% \mathrm{SiO}_{2}(30.0 \mathrm{~nm})$, (D) FEVE with $30.0 \mathrm{wt} \% \mathrm{TiO}_{2}(300.0 \mathrm{~nm})$ and $20.0 \mathrm{wt} \% \mathrm{SiO}_{2}(30.0 \mathrm{~nm})$.

Fig.9. (A) Tafel polarization curves and (B) Nyquist plots of various coatings covered metal, (a) pure FEVE, (b) FEVE with $30.0 \mathrm{wt} \% \mathrm{TiO}_{2}(300.0 \mathrm{~nm})$, (c) FEVE with $30.0 \mathrm{wt} \% \mathrm{TiO}_{2}(300.0 \mathrm{~nm})$ and $15.0 \mathrm{wt} \% \mathrm{SiO}_{2}(30.0 \mathrm{~nm})$, (d) FEVE with $30.0 \mathrm{wt} \% \mathrm{TiO}_{2}$ (300.0nm) and $20.0 \mathrm{wt} \% \mathrm{SiO}_{2}(30.0 \mathrm{~nm})$.

Table 1.

\begin{tabular}{|c|c|c|c|c|c|c|}
\hline Sample & $\begin{array}{c}\text { Contact } \\
\text { angle }\end{array}$ & $\begin{array}{c}E_{\text {corr }} \\
(\mathrm{V})\end{array}$ & $\begin{array}{c}I_{\text {corr }} \\
\left(\mathrm{A} / \mathrm{cm}^{2}\right)\end{array}$ & $\begin{array}{c}R_{p} \\
\left(\mathrm{M} \Omega \mathrm{cm}^{2}\right)\end{array}$ & $\begin{array}{c}R_{c t} \\
\left(\mathrm{~K} \Omega \mathrm{cm}^{2}\right)\end{array}$ & $\begin{array}{c}V_{\text {corr }} \\
(\mathrm{mm} / \text { year })\end{array}$ \\
\hline $\mathrm{FEVE}$ & 88.3 & -0.92 & $5.25 \times 10^{-8}$ & $1.42 \times 10^{3}$ & 67.87 & $16.95 \times 10^{-4}$ \\
\hline $\begin{array}{c}\mathrm{FEVE} / \mathrm{TiO}_{2} \\
\mathrm{FEVE} / \mathrm{TiO}_{2}(30) / \\
\mathrm{SiO}_{2}(15)\end{array}$ & 92.6 & -0.61 & $1.02 \times 10^{-8}$ & $4.78 \times 10^{3}$ & 76.06 & $3.29 \times 10^{-4}$ \\
\hline $\begin{array}{c}\mathrm{FEVE} / \mathrm{TiO}_{2}(30) / \\
\mathrm{SiO}_{2}(20)\end{array}$ & 166.3 & -0.25 & $2.61 \times 10^{-10}$ & $4.1 \times 10^{5}$ & 410 & $8.44 \times 10^{-6}$ \\
\hline
\end{tabular}

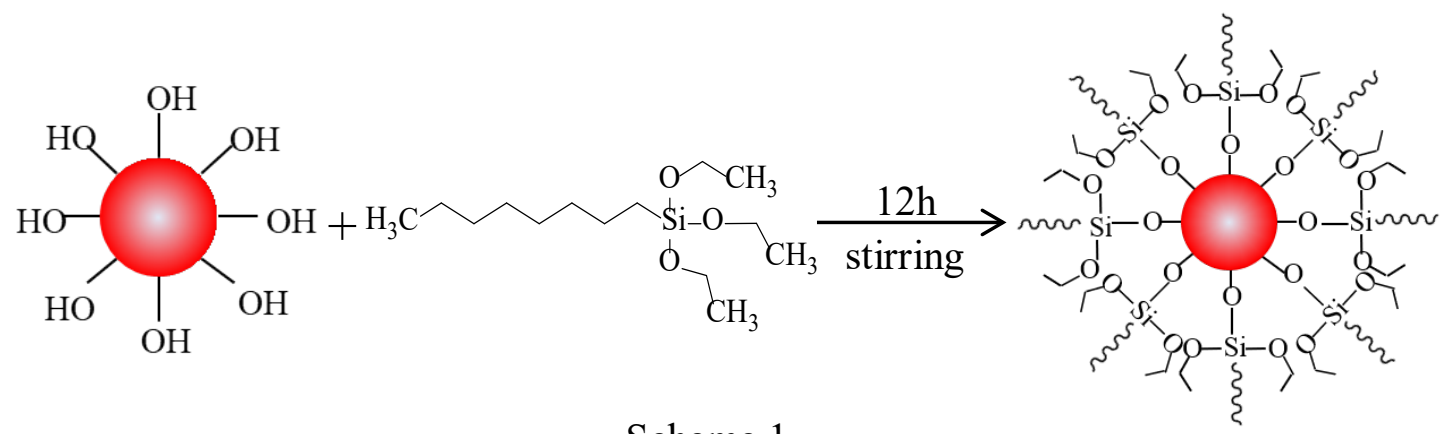

Scheme 1. 

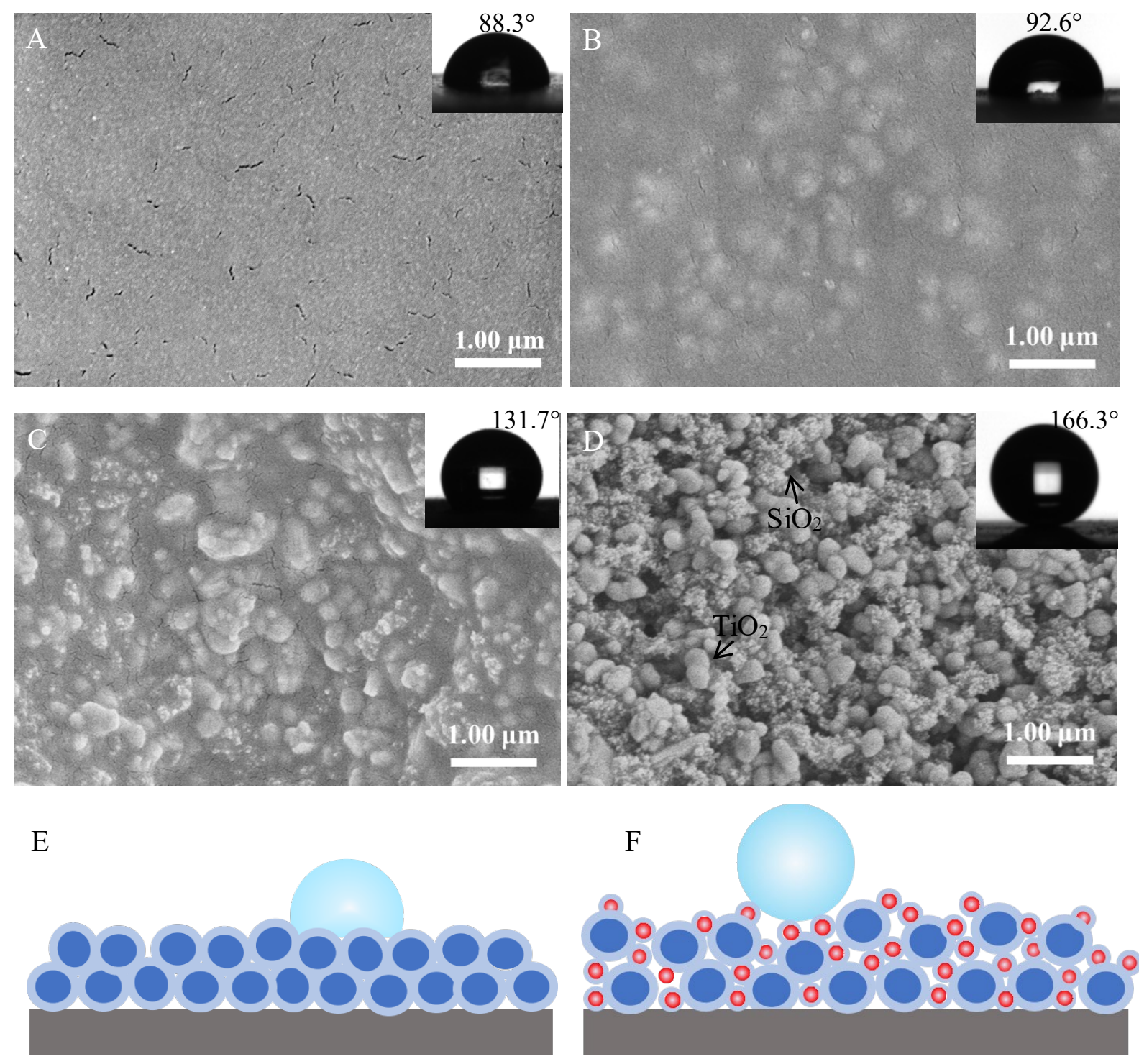

Fig.1. 

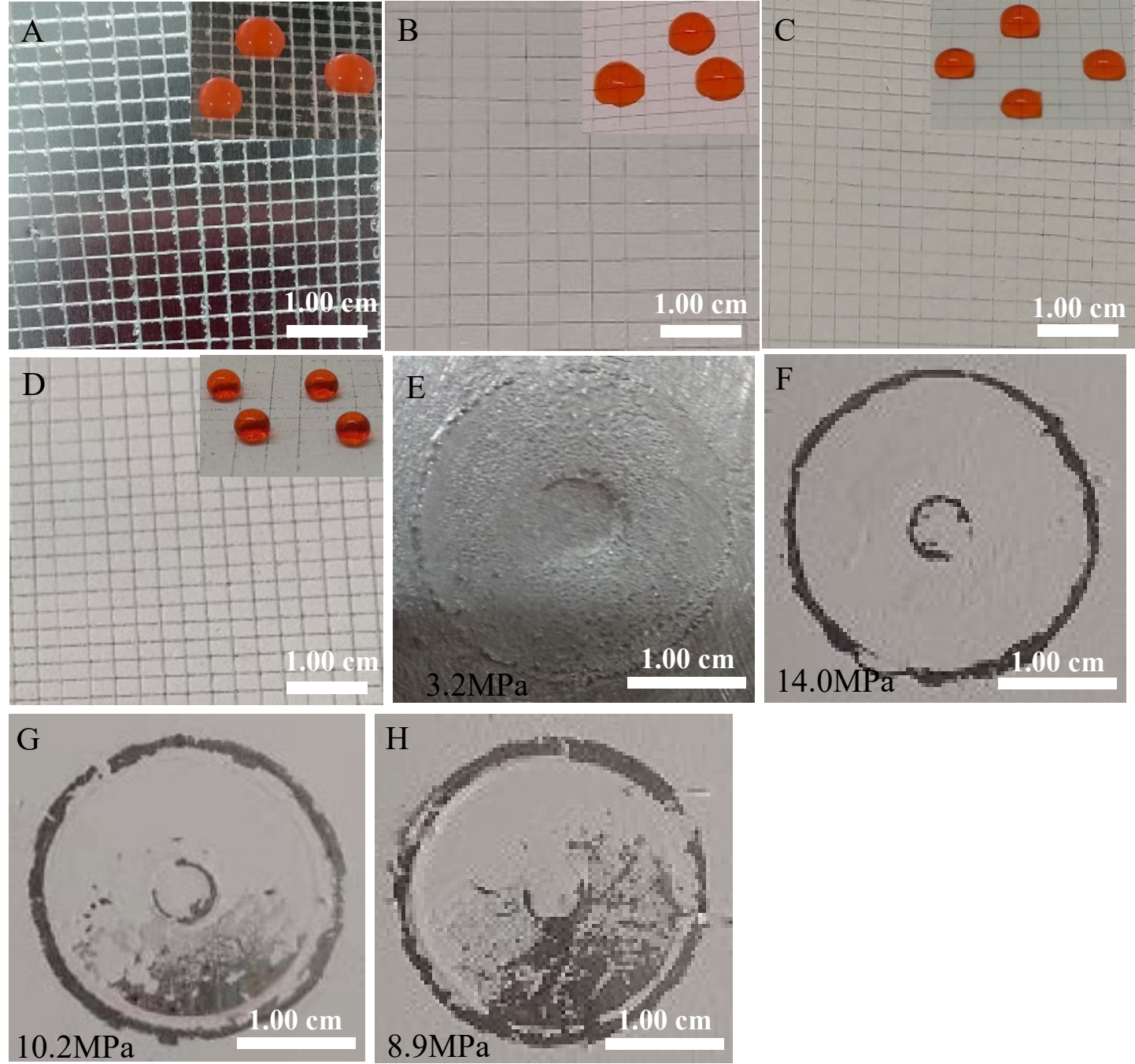

Fig. 2 . 

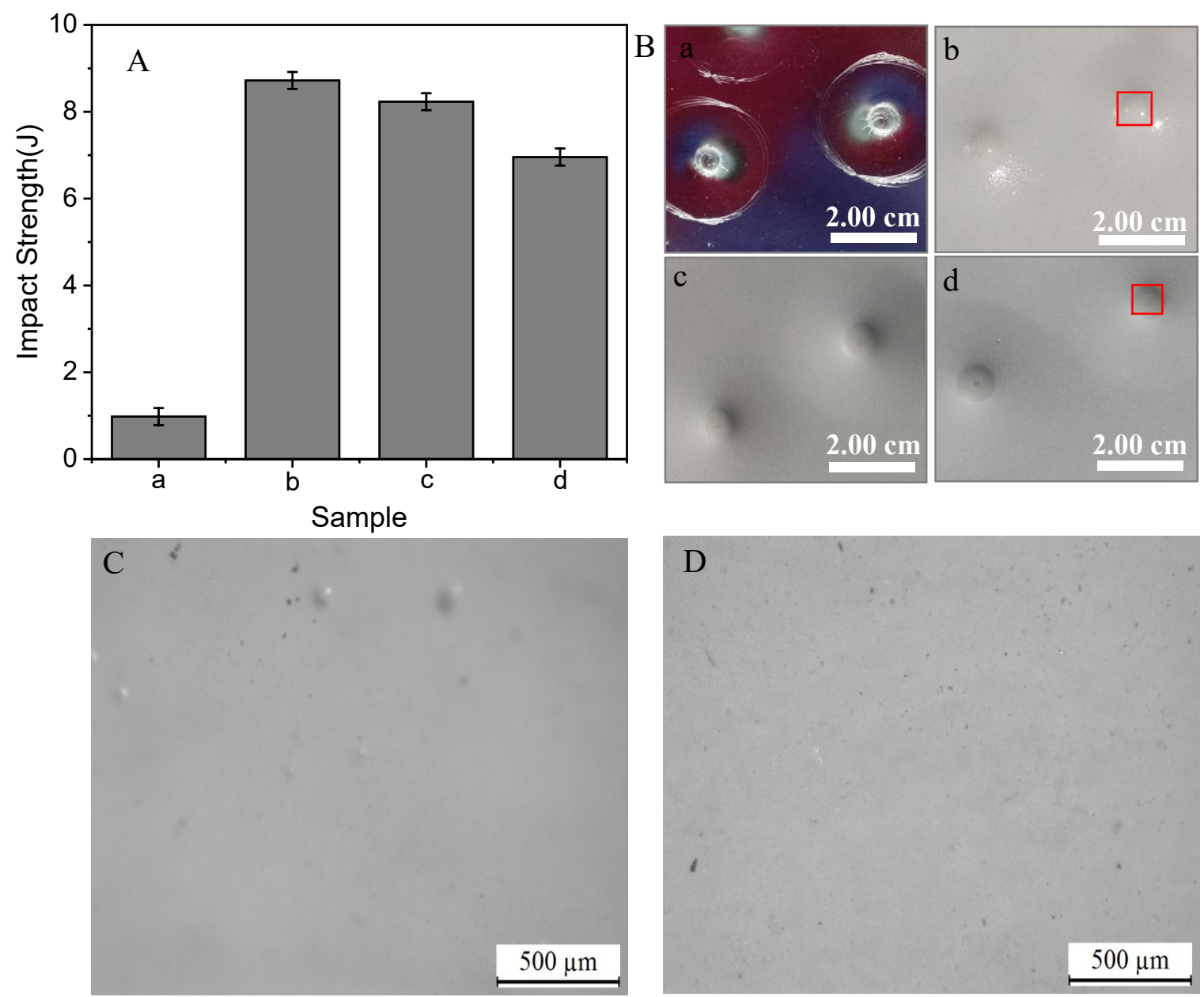

Fig.3. 

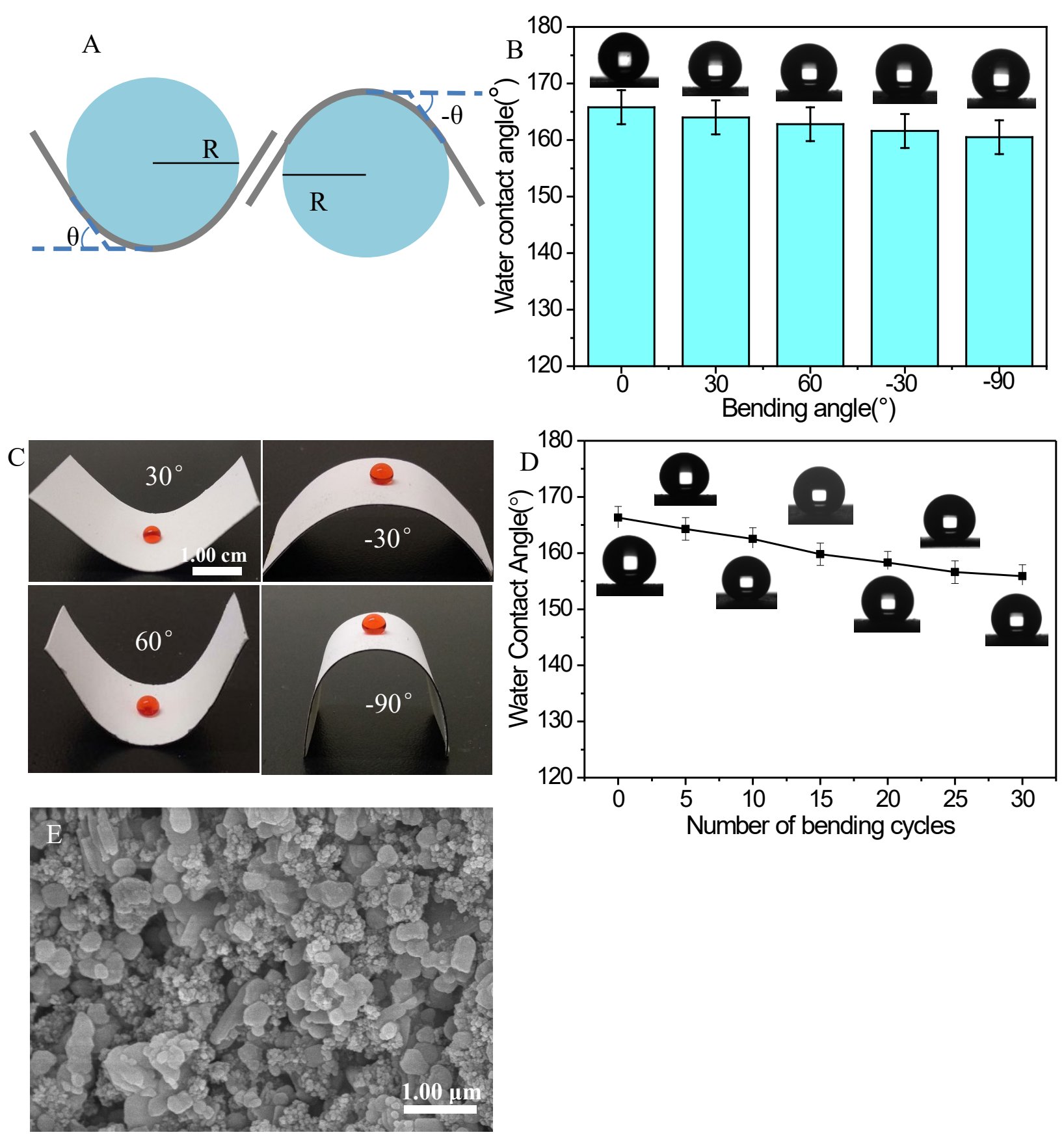

Fig.4. 

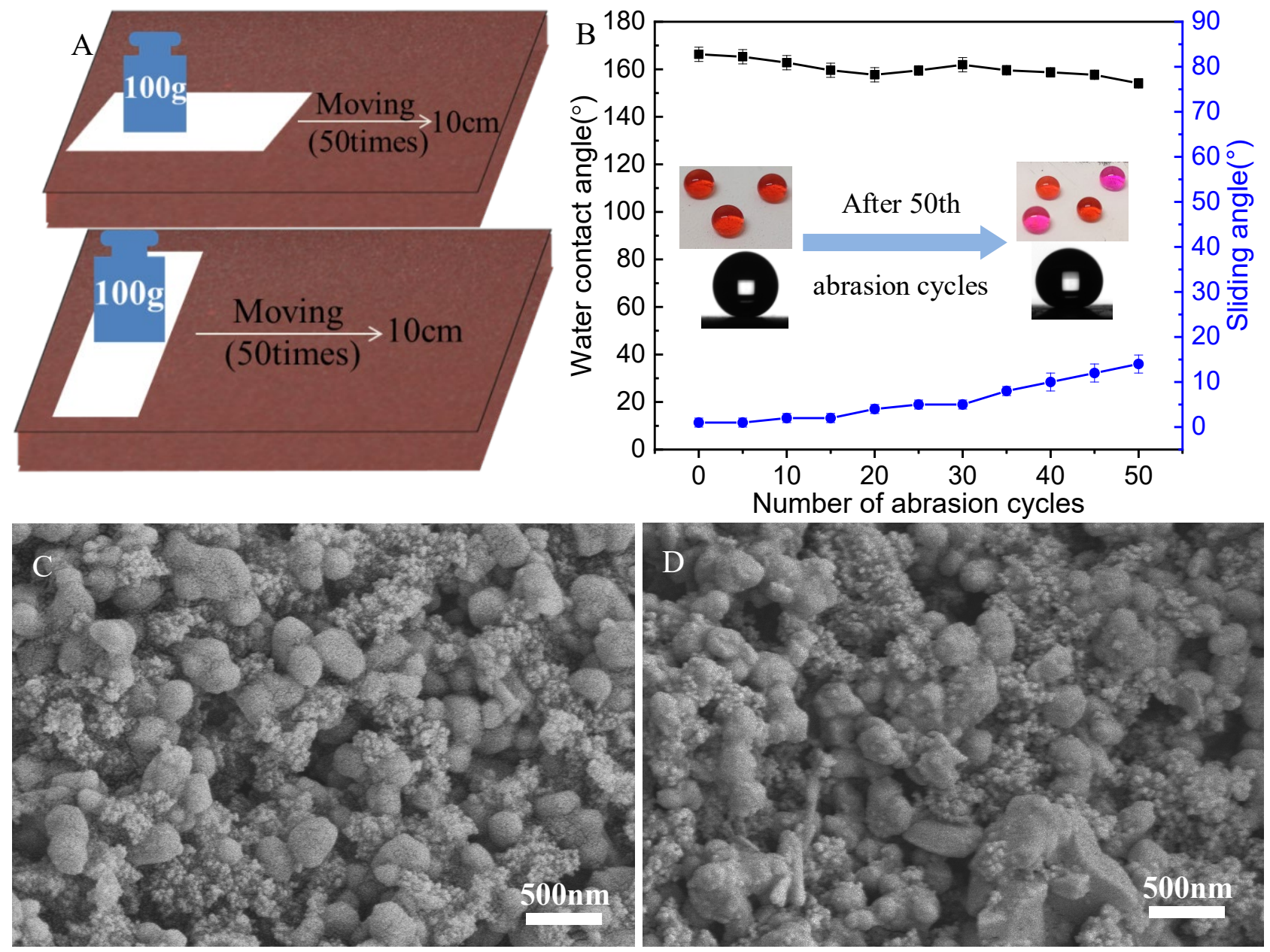

Fig.5. 

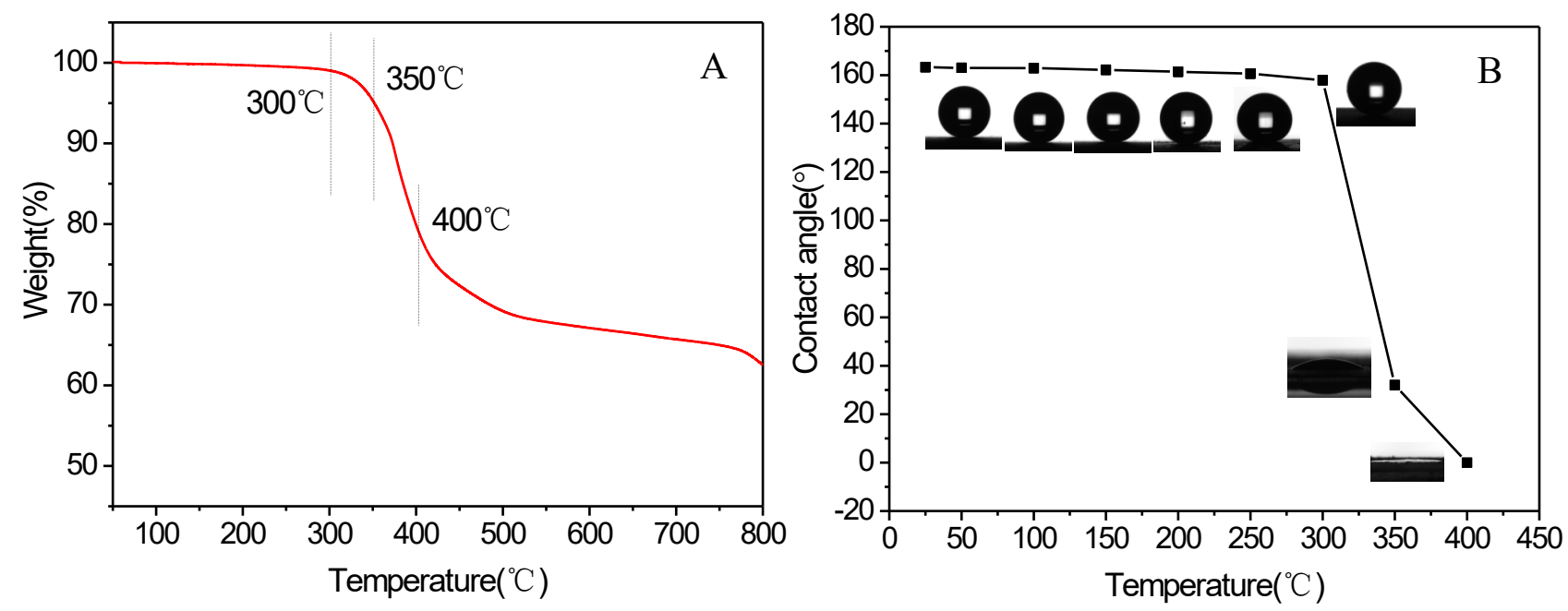

Fig.6. 

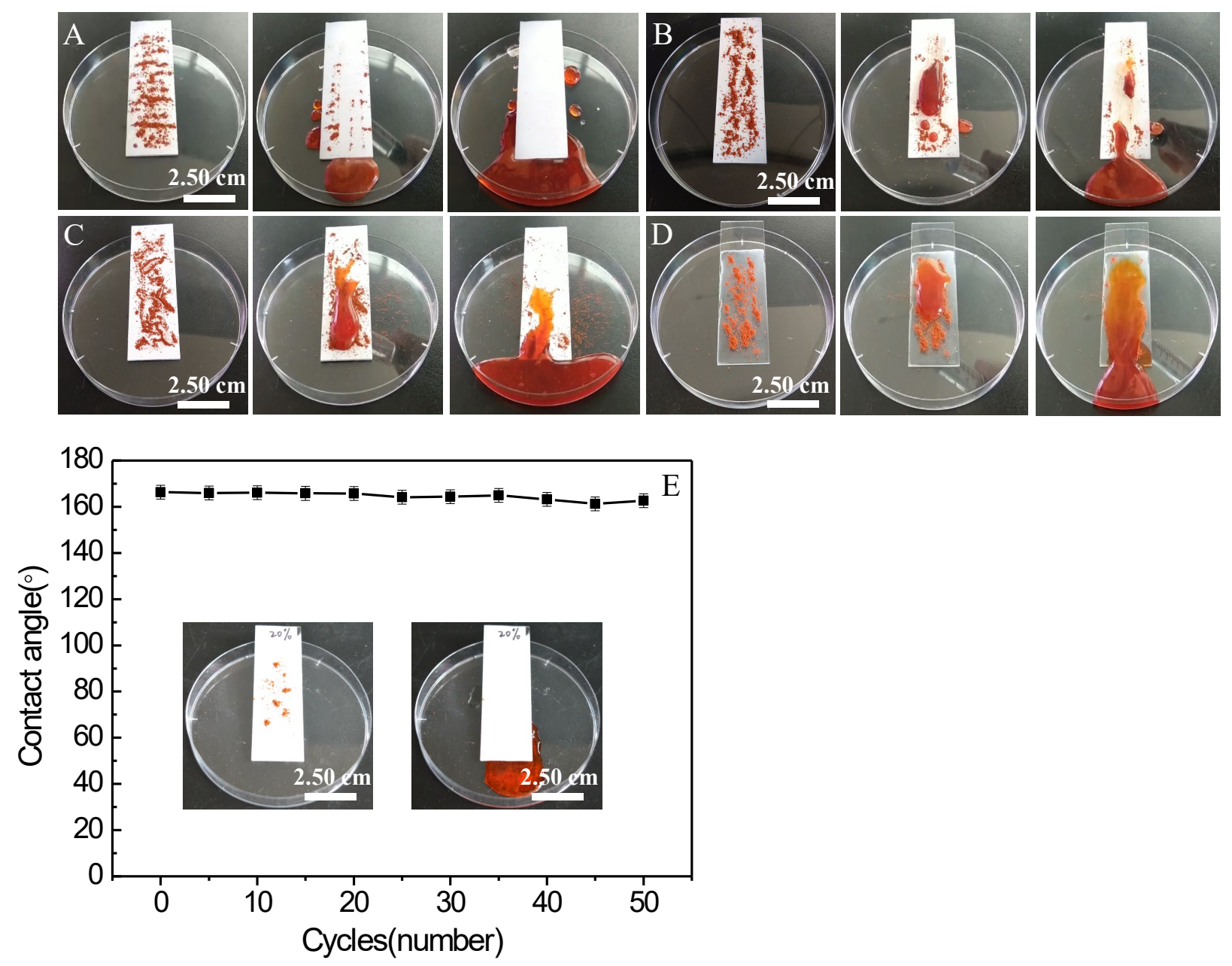

Fig.7. 


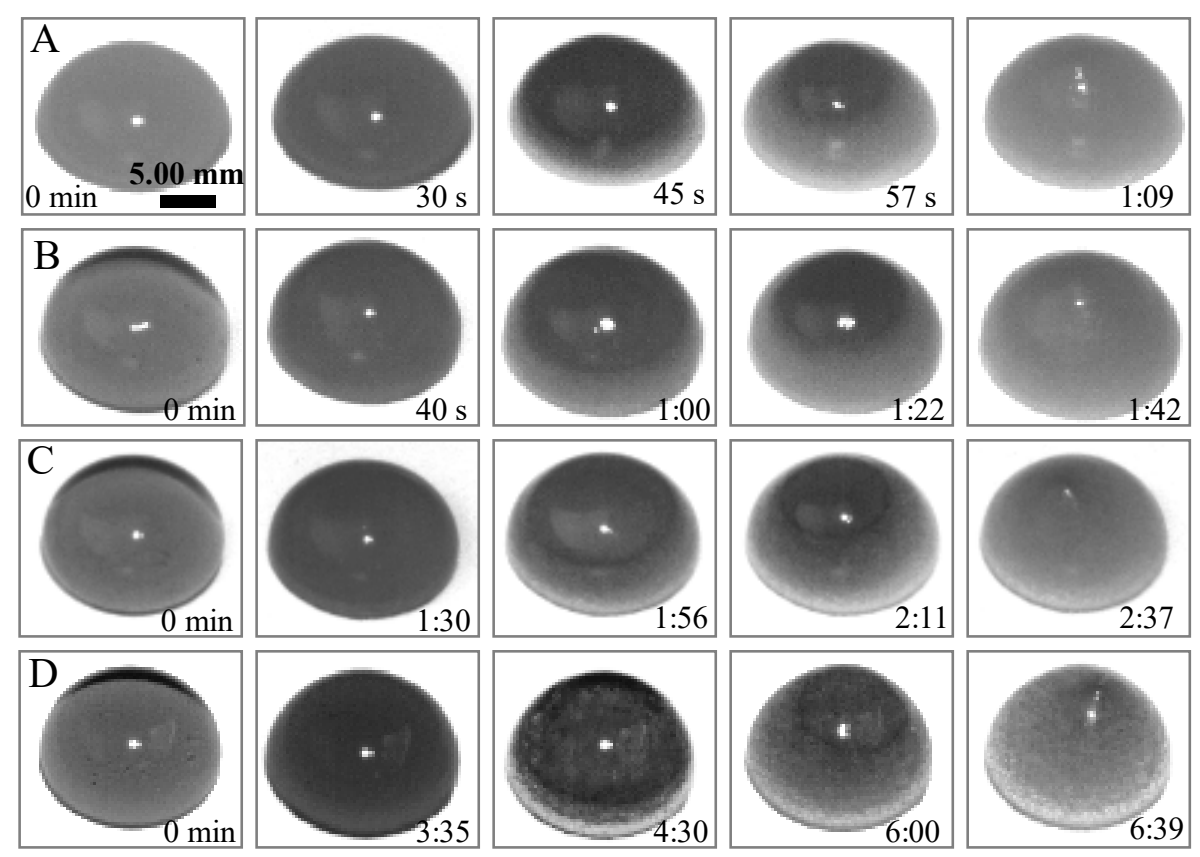

Fig.8. 

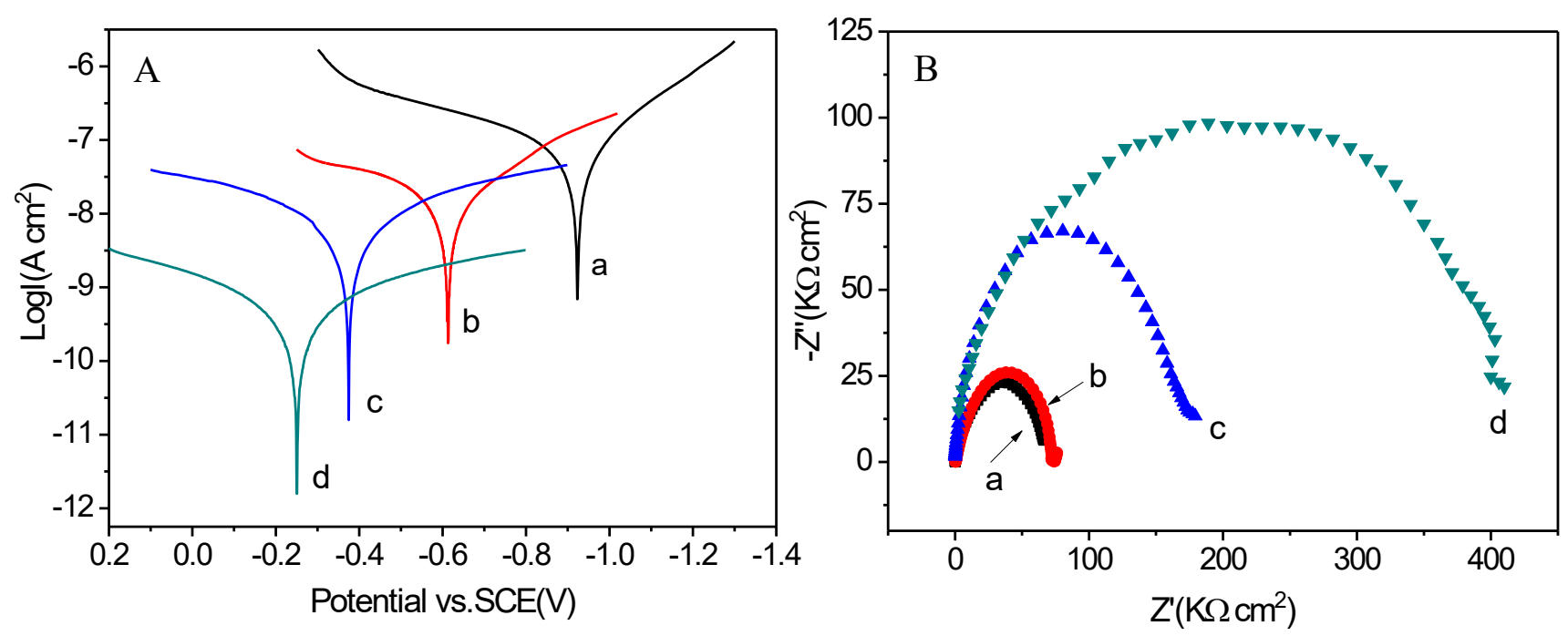

Fig.9. 